\title{
Effect-site concentration of remifentanil for preventing cough during emergence in elderly patients: A comparison with adult patients
}

\author{
Yun Jeong Chae ${ }^{1}$, Yun Yong Jeong ${ }^{1}$, Ji Young Yoo ${ }^{1}$, Sung Yong Park ${ }^{1}$, Sook Young Lee', \\ Jong Yeop Kim ${ }^{1}$
}
1 Department of Anaesthesiology and Pain Medicine, Ajou University School of Medicine, Suwon, Korea

\section{$\underline{\text { Purpose }}$}

Prevention of cough during emergence after nasal surgery is important to avoid cardiovascular change, laryngospasm, and bleeding from the surgical site. We designed this study to investigate remifentanil effect-site concentration in $50 \%$ of patients (EC50) for smooth emergence without cough in elderly patients, and to compare it with that in adult patients undergoing nasal surgery.

\section{$\underline{\text { Methods }}$}

Elderly patients (65-80 yrs) and adult patients (20-60 yrs) with ASA physical status I or II undergoing nasal surgery were enrolled in this study. Anesthesia was maintained with sevoflurane and remifentanil via TCI system (Orchestra ${ }^{\circledR}$, Fresenius Vial, France) using Minto's model. The Dixon's up and down method was used to determine the effect-site concentration of remifentanil for cough suppression during emergence period. The initial effect-site concentration of remifentanil was $1.8 \mathrm{ng} / \mathrm{ml}$. In the next patient, effect-site concentration of remifentanil was decreased or increased by a step of $0.4 \mathrm{ng} / \mathrm{ml}$. EC50 of remifentanil was determined by calculating the mean of the midpoint effect-site concentration of all independent pairs after six crossover points were obtained (i.e. success to failure). EC50 and EC95 of remifenanil were determined using isotonic regression method with bootstrapping approach. In addition, recovery profiles were recorded.

\section{$\underline{\text { Results }}$}

A total of 47 patients completed the study : 22 patients of mean age 69 (elderly group), and 25 patients of mean age 35 (adult group). The number of ASA physical status II was more in the elderly group significantly $(\mathrm{P}<0.001)$. The sequence of dose-response data for each patient obtained are shown in Fig. 1. Using the modified Dixon's up-and-down method, EC50 of remifentanil was not significantly different between the elderly and adult groups $(2.40 \pm$ $0.25 \mathrm{ng} / \mathrm{ml}$ vs. $2.33 \pm 0.30 \mathrm{ng} / \mathrm{ml}$, respectively, $\mathrm{P}=0.687)$. Using isotonic regression and bootstrapping approach, EC50 of remifentanil was similar in the elderly and adult groups $[2.50(83 \%$ CI, 2.38-2.75 ng/ml) and 2.52 (83 CI, 2.29-2.78 ng/ml), respectively]. EC95 of remifentanil was also similar in the elderly and adult groups [3.32 (95\% CI, 3.06-3.38 ng/ml) and $3.30(95 \%$ CI, 2.96-3.37 ng/ml), respectively]. Recovery profiles are presented in Table 1.

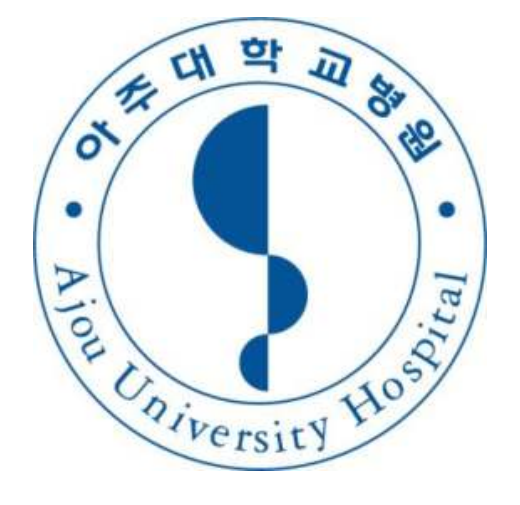

Fig 1. The sequence of dose-response data
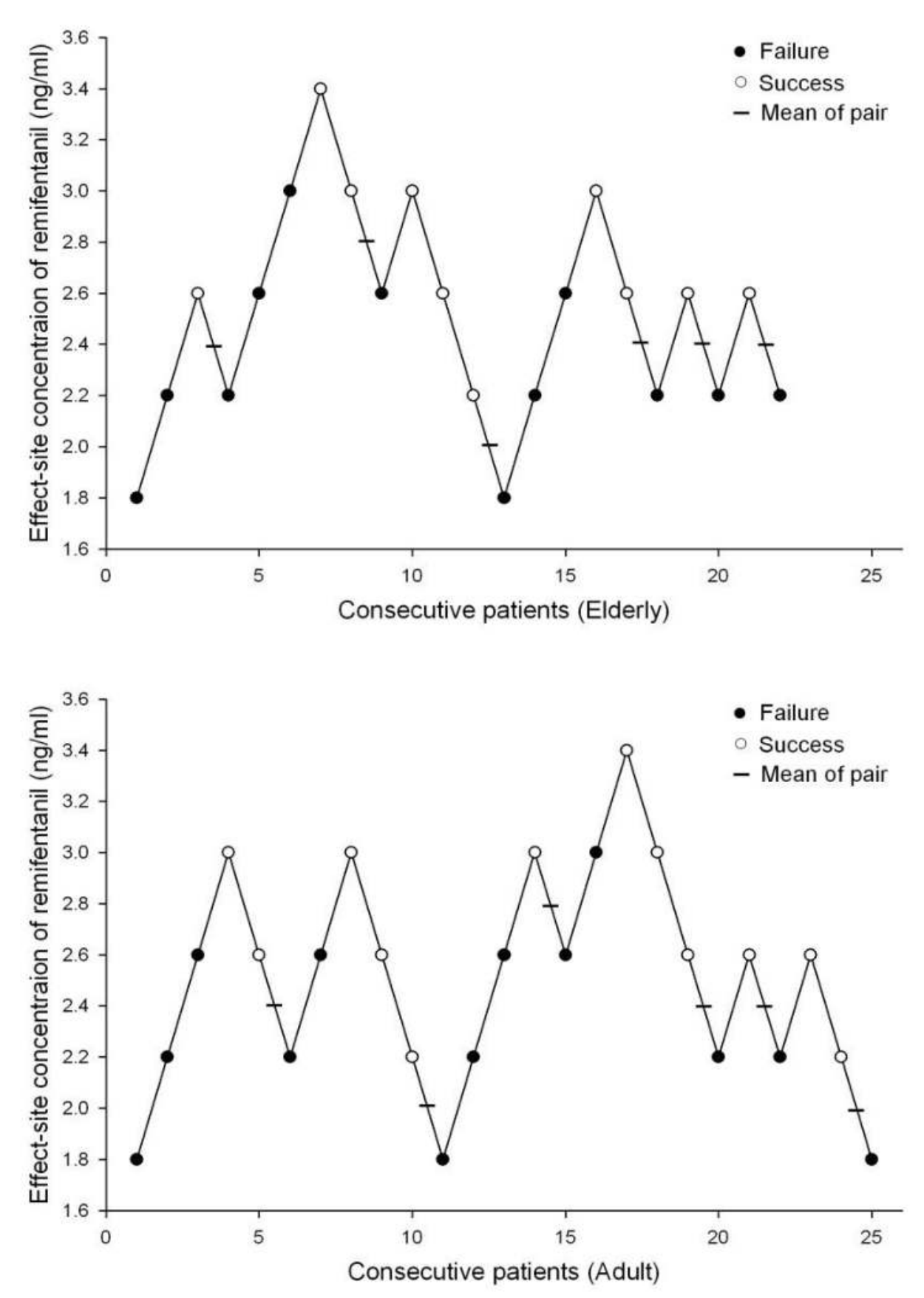

Table 1 . Recovery profiles

\begin{tabular}{lccc}
\hline & Elderly $(\mathrm{n}=22)$ & Adult $(\mathrm{n}=25)$ & P-value \\
\hline Operation time (min) & $34.1 \pm 11.5$ & $35.2 \pm 14.8$ & 0.777 \\
Anesthesia time (min) & $70.4 \pm 12.1$ & $71.9 \pm 17.1$ & 0.733 \\
Eye opening (min) & $14.1 \pm 3.8$ & $12.0 \pm 2.9$ & 0.035 \\
Extubation time (min) & $17.2 \pm 4.1$ & $14.0 \pm 3.0$ & 0.004 \\
PACU stay (min) & $44.5 \pm 7.6$ & $38.7 \pm 3.4$ & 0.002 \\
Pain at PACU (NRS) & $3[3-4]$ & $3[3-4.25]$ & 0.302 \\
Additional analgesics & 4 & 4 & 0.835 \\
SpO ${ }_{2}<95 \%$ & 1 & 0 & 0.468 \\
$\mathrm{RR}^{2} 8$ beats/min & $8(36 \%)$ & $6(24 \%)$ & 0.355 \\
\hline
\end{tabular}

\section{$\underline{\text { Conclusion }}$}

In the elderly patients, effect-site concentration of remifentanil for preventing cough after nasal surgery from sevoflurane anaesthesia did not differ in the adult patients. However, delayed awakening and respiratory adverse events might warrant special attention in the elderly patients. 